\title{
The fate of burned areas in the Mato Grosso and Pará Brazilian Amazon States
}

\author{
Taise Farias Pinheiro ${ }^{1}$, Nara Vidal Pantoja ${ }^{2}$
}

\footnotetext{
${ }^{1}$ National Institute for Space Research (INPE)/Forest Investment Project Cerrado;

${ }^{2}$ Institute of the Environment and Renewable Natural Resources (IBAMA);

*e-mail: taisefarias@ hotmail.com; nara.pantoja@ibama.gov.br
}

\begin{abstract}
Given the regional complexity and dynamic, Amazônia has been targeted by permanent monitoring systems since the 1980s. PRODES (Monitoring Brazilian Amazon Forest by Satellite), created in 1988, delivers the yearly deforestation rate assessment, mapping the occurrence of clear-cutting. As other human-caused forest disturbances, such as from fire and selective timber harvesting, became common throughout Amazonia, a new and complementary system was created. In 2004, a warning system, called DETER (NearReal-time Deforestation Detection), was designed to deliver daily warnings to guide environmental enforcement. DETER maps the occurrence of clear-cutting and the longterm and gradual reduction of canopy cover due to forest fire and unsustainable logging, known as forest degradation. Considering that fire-driven deforestation is the major source of carbon emissions from Amazonia, we analyze whether the fate of the burned forest is the clear-cut. To do this, we used data for the 08/01/2017 to 07/31/2018 period and compared the DETER class "burn-scarred vegetation" with the PRODES class "clear-cut". We selected Mato Grosso and Pará states, hotspots of deforestation in the Amazon region. The Pará state had both the highest burn-scarred vegetation $\left(9105 \mathrm{Km}^{2}\right)$ and clear-cutting areas $\left(2590 \mathrm{Km}^{2}\right)$ compared with Mato Grosso, which displays $8020,27 \mathrm{Km}^{2}$ and $1339 \mathrm{Km}^{2}$, respectively. The burned area was then intersected with the clear-cut map. The result shows that $1 \%\left(94,4 \mathrm{Km}^{2}\right)$ and $1,6 \%\left(129 \mathrm{Km}^{2}\right)$ of the detected burned vegetation were converted to cleared land in the Para and Mato Grosso, respectively. A forest fire can alter radically forest structure and easily lead it into clear-cut. Also, deforestation has long been associated with fire, and thus it was expected to find a higher proportion of burned areas converted to cleared land. We hypothetized that, in the analyzed period, DETER has detected mainly scars of a low-intensity forest fire. Besides, we hypothetized that there is a regime of recurrent antropogenic interventions in the forest before total vegetation removal. Thus, if apropriated surveillance actions are taken is possible avoiding that this process results in clearings.
\end{abstract}

Keywords: forest degradation, remote sensing, land cover changes monitoring, Amazon region 